\title{
A NUMERICAL ALGORITHM FOR SOLVING INVERSE FILTRATION PROBLEMS WITH THE POINTWISE OVERDETERMINATION
}

\author{
S. N. Shergin, Yugra State University, Khanty-Mansiysk, Russian Federation, \\ ssn@ugrasu.ru
}

The inverse problems of recovering the right-hand side in a pseudoparabolic equations of filtration with the use of the pointwise overdetermination are studied. We expose some existence and uniqueness theorems which are the base of an numerical algorithm of recovering the right-hand side (the source function) and a solution. The problem is well-posed and the stability estimates hold. It can be reduced to a Volterra-type integral equation, where the operator has a small norm for small time segments. The finite element method is used to reduce the problem to a system of ordinary differential equations which is solved by the finite difference method. The idea of the predictor-corrector method is employed in the algorithm. The results of numerical experiments are presented. They show a good convergence of an approximate solutions to a solution.

Keywords: inverse problem; pseudoparabolic equation; filtration; fissured rock; numerical solution.

\section{Introduction}

In the present article we consider an inverse problem of recovering the right-hand side in a Sobolev-type equation of the third order. These equations belong to the class of equation unsolvable with respect to higher derivatives. The systematical study of equations of this class began with the S. L. Sobolev articles (see [1]). Afterwards, S. L. Sobolev's results were generalized by many authors. We can refer to the known results by S. A. Galpern, S. G. Krein, M. I. Vishik, R. Schowalter, T. I. Zelenyak, G. V. Demidenko, S. I. Uspenskii, and many other authors (see the bibliography in [2]). The most known third order Sobolev-type models are the equation of Rossby waves [3] proposed by C. G. Rossby in 1939 and the filtration theory equations derived by G. I. Barenblatt, Iu. P. Zheltov and I. N. Kochina [4] in 1960. The latter model is written as

$$
u_{1 t}-\eta \Delta u_{1 t}-k \Delta u_{1}=0
$$

where the parameter $k$ corresponds to the piezo-conductivity of fissured rock and $u$ is the pressure. The dimensionless coefficient $\alpha$ characterizes the intensity of the liquid transfer between the blocks and fissures. More general models can include nonlinearities arising from fluid type (a liquid or a gas), concentration (porosity, absorption or saturation) and the exchange rate [5].

General equations of the form (1) can be written as follows:

$$
L(t, x, D) u_{t}-M(t, x, D) u=f,(x, t) \in Q=G \times(0, T)
$$

where $L, M$ are second order operators and $G$ is a bounded domain in $\mathbb{R}^{n}$. The equation (2) is furnished with initial and boundary conditions of the form

$$
u(0, x)=u_{0}(x),\left.\quad R u\right|_{S}=g(t, x)
$$


with $R u=u$ or $R u=\sum_{i=1}^{n} \gamma_{i}(t, x) u_{x_{i}}+\sigma(t, x) u$ (other boundary conditions are also possible). We look for the right-hand side $f$ of the form

$$
f=\sum_{i=1}^{r} q_{i}(t) f_{i}(t, x)+f_{0}(t, x), \quad f_{i} \in L_{\infty}\left(0, T ; L_{p}(G)\right),
$$

Our problem is stated as follows: find the functions $\left\{q_{i}(t)\right\}_{i=1}^{r}$ and a solution $u$ to the problem (2)-(3) such that

$$
u\left(t, y_{i}\right)=\psi_{i}(t), \quad(i=1,2, . ., r),
$$

where $y_{i}$ are arbitrary points lying in $G$ and $f_{i}(t, x)$ are given functions.

Sobolev-type equations of the form (2) with various differential operators $L_{1}$ and $L_{2}$ of even order in the spacial variables also arise in the mathematical models of the heat conduction, wave processes, quasistationary processes in semiconductors and magnetics, in the models for filtration of the two-phase flow in porous media with the dynamic capillary pressure (see [7, 36], [6] and the bibliography therein). Detailed bibliography and the results concerning the solvability of direct problems for Sobolev-type equations and their abstract analogs can be found, for instance, in [9, 8, 10, 38, 37]. The first results devoted to inverse problems for pseudoparabolic equations were obtained in [11], where an inverse problems of recovering an unknown source $f$ of a special form in (2) is considered. Large number of results is exposed in the monographs [13], [12]). The problems of recovering coefficients, in particular, the coefficients $k(t)$ and $\eta$ are studied in $[16,17,18]$, where integral overdetermination conditions are used. The problem (1)-(5) is considered in [19, $20,21]$ and it is proven that this problem is uniquely solvable under natural conditions for the data. Closed results on recovering the right-hand side of the form $f(t) g(x)$ (the function $f(t)$ is not known) are exposed in $[14,15]$ even for more general classes of the equations. Exposition of numerical methods for solving inverse problem can be found, for instance, in [22, 23]. We can refer also to the articles [25, 28, 27, 30, 31, 32, 29, 39] devoted to different numerical methods of solving boundary value problems for Sobolevtype equations. At the same time, the number of articles devoted to numerical solving inverse problems for Sobolev-type equations is rather limited (see, for instance, [33, 32, 34]. Most of the articles are devoted to different model problems. Some numerical methods for solving filtration problems of the form (2)-(5) but for simpler models are presented in [24]. Here the Sobolev-type equation for the pressure is replaced with a parabolic one.

We use the theoretical results exposed in [19, 20, 21], where the existence and uniqueness theory as well as the stability estimates for solutions can be found, describe numerical methods applicable to a wide class of inverse problems with the pointwise ovedetermination of the form (2)-(5), and present the results of numerical experiments.

\section{Preliminaries}

We consider a general inverse problem on recovering functions occurring into the right-hand side of the equation. We assume that

$$
L=\sum_{i, j=1}^{n} a_{i j}(t, x) \partial_{x_{i} x_{j}}+\sum_{i=1}^{n} a_{i}(t, x) \partial_{x_{i}}+a_{0}(t, x)
$$


and the operator $M$ is representable as

$$
M u=\sum_{i, j=1}^{n} b_{i j}(t, x) u_{x_{i} x_{j}}+\sum_{i=1}^{n} b_{i}(t, x) u_{x_{i}}+b_{0}(t, x) u,
$$

Put $(u, v)=\int_{G} u(x) v(x) d x$. All function spaces as well as coefficients of the equations are assumed to be real.

We employ the Sobolev spaces $W_{p}^{s}(G)$ and Hölder spaces $C^{\alpha}(\bar{G})$ (see the definitions in [35]). The symbol $L_{p}(0, T ; H)$ ( $H$ is a Banach space) stands for the space of strongly measurable functions defined on $[0, T]$ with values in $H$. Given an interval $J=(0, T)$ and a domain $G \in \mathbb{R}^{n}$, put $Q=(0, T) \times G$ and $W_{p}^{r, s}(Q)=W_{p}^{r}\left(J ; L_{p}(G)\right) \cap L_{p}\left(J ; W_{p}^{s}(G)\right)$. Respectively, $W_{p}^{r, s}(S)=W_{p}^{r}\left(J ; L_{p}(\Gamma)\right) \cap L_{p}\left(J ; W_{p}^{s}(\Gamma)\right)(S=(0, T) \times \partial G)$. Similarly, we can define the Hölder spaces $C^{r, s}(\bar{Q})$.

Next, we describe the condition on the data of the problem. We assume that the operator $L$ is elliptic, i. e., there exists a constant $\delta>0$ such that

$$
\sum_{i, j=1}^{m} a_{i j} \xi_{i} \xi_{j} \geq \delta_{0}|\xi|^{2} \quad \forall \xi \in R^{n}, \quad \forall(t, x) \in \bar{Q} .
$$

Fix a parameter $p>n$ and assume that

$$
\begin{gathered}
b_{i j} \in L_{\infty}(Q), b_{i}, b_{0} \in L_{\infty}\left(0, T ; L_{p}(G)\right), \\
a_{i j} \in C(\bar{Q}), \quad a_{i}, a_{0} \in C\left([0, T] ; L_{p}(G)\right) \quad(i, j=1,2, . ., n) ;
\end{gathered}
$$

a) $a_{0}(t, x) \leq 0$ a.e. (almost everywhere) in $Q$ in the case of the Dirichlet boundary conditions and $a_{0}^{0} \leq 0$ a.e. in $Q$ and $a_{0}^{0}<0$ a.e. in some neighborhood about $S$ in the case of the oblique derivative problem;

$$
\begin{gathered}
\gamma_{i}, \gamma_{i t}, \sigma, \sigma_{t} \in C^{1 / 2,1}(\bar{S}), i=1,2, \ldots, n . \\
\psi_{i}(0)=u_{0}\left(y_{i}\right)(i=1,2, . ., r),\left.R(0, x, D) u_{0}\right|_{\Gamma}=g(0, x) .
\end{gathered}
$$

Let $s_{0}=2-1 / p$ in the case of the Dirichlet boundary conditions and $s_{0}=1-1 / p$ otherwise. Construct a matrix $B$ with the rows

$$
L^{-1} f_{1}\left(t, y_{j}\right), . ., L^{-1} f_{r}\left(t, y_{j}\right)
$$

where $j=1,2, \ldots, r$ and assume that the there exists a constant $\delta_{0}>0$ such that

$$
|\operatorname{det} B| \geq \delta_{0} \quad \forall t \in[0, T] .
$$

Here $L^{-1} f_{i}$ is a solution $U_{i}$ to the problem $L U_{i}=f_{i},\left.U_{i}\right|_{t=0}=0,\left.R U_{i}\right|_{S}=0$.

The following theorem follows from the results in [20], [21].

Theorem 1. Let the conditions (6)-(11) be fulfilled and let

$$
\begin{gathered}
f_{0} \in L_{p}(Q), f_{i} \in L_{\infty}\left(0, T ; L_{p}(G)\right), \quad u_{0}(x) \in W_{p}^{2}(G), \\
g_{t} \in L_{p}\left(0, T ; W_{p}^{s_{0}}(G)\right), \psi_{i} \in W_{p}^{1}(0, T), i=1,2, \ldots, r, \quad p>n .
\end{gathered}
$$


Then there exists a unique solution to $\left(u, q_{1}, \ldots, q_{r}\right)$ the problem (2)-(5) such that

$$
u \in W_{p}^{1}\left(0, T ; W_{p}^{2}(G)\right), \quad q_{i}(t) \in L_{p}(0, T)(i=1,2, \ldots, r) .
$$

A solution satisfies the estimate

$$
\begin{aligned}
\|u\|_{W_{p}^{1}\left(0, T ; W_{p}^{2}(G)\right)}+\sum_{i=1}^{r}\left\|q_{i}(t)\right\|_{L_{p}(0, T)} \leq & \\
& c\left(\left\|f_{0}\right\|_{L_{p}(Q)}+\left\|g_{t}\right\|_{L_{p}\left(0, T ; W_{p}^{s_{0}}(G)\right)}+\sum_{i=1}^{r}\left\|\psi_{i}\right\|_{W_{p}^{1}(0, T)}\right) .
\end{aligned}
$$

This theorem actually justifies the numerical algorithm presented below and the scheme of the algorithm is taken from its proof.

\section{Description of the Algorithm}

To simplify the presentation, we describe the idea of the algorithm in the model case. We rely on some integral identities. Consider the problem

$$
\begin{aligned}
& L_{0} u_{t}+k(t) L_{1} u=f=f_{0}+\sum_{i=1}^{r} q_{i}(t) f_{i}(x, t), \\
& \left.\frac{\partial u}{\partial n}\right|_{\Gamma}=g, \quad u(0, x)=u_{0}(x), \\
& u\left(y_{i}, t\right)=\psi_{i}(t), \quad i=1,2, \ldots, r,
\end{aligned}
$$

where

$$
\begin{gathered}
L_{0} u=-\operatorname{div}\left(a_{0}(x, t) \nabla u_{t}\right)+b_{0}(x, t) \cdot \nabla u+c_{0}(x, t) u, \\
L_{1} u=-\operatorname{div}\left(a_{1}(x, t) \nabla u\right)+b_{1}(x, t) \cdot \nabla u+c_{1}(x, t) u,
\end{gathered}
$$

and $a_{0}, a_{1}, c_{0}, c_{1}$ are scalar functions and $b_{0}, b_{1}$ are vector-function of length $n$. The functions $u$ and $q_{i}(t)$ are unknown. We assume that all conditions of Theorem 1 for the data are fulfilled. Let $\varphi \in L_{q}\left(0, T ; W_{q}^{1}(G)\right)(1 / q+1 / p=1)$ be a test function and let a function $u$ be a solution to the problem (12), (13) from the class pointed out in Theorem 1. Integrating by parts in the identity

$$
\left(L_{0} u_{t}, \varphi\right)+k(t)\left(L_{1} u, \varphi\right)=(f, \varphi), \varphi \in L_{q}\left(0, T ; W_{q}^{1}(G)\right)
$$

we arrive at the equality

$$
\left.a\left(u_{t}, \varphi\right)+k(t) b(u, \varphi)=l(\varphi)+k(t) l_{1}(\varphi)+\sum_{k=1}^{r} q_{k}(t)\left(f_{k}, \varphi\right)\right),
$$

where $a\left(u_{t}, \varphi\right)=\left(a_{0} \nabla u_{t}, \nabla \varphi\right)+\left(b_{0} \cdot \nabla u_{t}+c_{0} u_{t}, \varphi\right), b(u, \varphi)=\left(a_{1} \nabla u, \nabla \varphi\right)+\left(b_{1} \cdot \nabla u+c_{1} u, \varphi\right)$, $l(\varphi)=\left(f_{0}, \varphi\right)+l_{0}(\varphi), l_{0}(\varphi)=\int_{\Gamma} a_{0} g_{t} \varphi d \Gamma, l_{1}(\varphi)=\int_{\Gamma} a_{1} g \varphi d t$

Next, we look for a solution $\varphi_{j}(x, t)(j=1,2, \ldots, r)$ to the problem

$$
L_{0}^{*} \varphi_{j}=\delta\left(x-y_{j}\right), \quad a_{0} \frac{\partial \varphi_{j}}{\partial n}+\left.b \cdot n \varphi_{j}\right|_{\Gamma}=0,
$$


where $L_{0}^{*}$ is a formally adjoint to $L_{0}$ and $\delta$ is the Dirac delta-function. Inserting $\varphi_{j}$ in (16), we obtain that

$$
\psi_{j t}+k(t)\left(b\left(u, \varphi_{j}\right)-l_{1}\left(\varphi_{j}\right)\right)=l\left(\varphi_{j}\right)+\sum_{k=1}^{r} q_{k}(t)\left(f_{k}, \varphi_{j}\right) .
$$

Hence, we conclude that

$$
\sum_{k=1}^{r} q_{k}(t)\left(f_{k}, \varphi_{j}\right)=\psi_{j t}+k(t)\left(b\left(u, \varphi_{j}\right)-l_{1}\left(\varphi_{j}\right)\right)-l\left(\varphi_{j}\right) .
$$

Note that the definition of $\varphi_{j}$ implies that

$$
\sum_{k=1}^{r} q_{k}(t)\left(f_{k}, \varphi_{j}\right)=\sum_{k=1}^{r} q_{k}(t) L^{-1} f_{k}\left(y_{j}, t\right) .
$$

Thus, this expression can be written as $R \vec{q}$ and in view of the condition (11) the determinant of the matrix $R$ does not vanish. The above integral identities allow us to construct the iteration procedure realized in the proof of Theorem 1 (see [19]-[21]). Let $\vec{q}_{0}=R^{-1} F_{0}$, with $F_{0 j}=\psi_{j t}+k(t)\left(b\left(u_{0}, \varphi_{j}\right)-l_{1}\left(\varphi_{j}\right)\right)-l\left(\varphi_{j}\right)$. Given a vector-function $\vec{q}_{i}$, we can construct $u^{i+1}$ as a solution to the problem (12), (13) with $\vec{q}=\vec{q}_{i}$ and to determine the next iteration $\vec{q}_{i+1}$ from the equalities

$$
\begin{gathered}
\vec{q}_{i+1}=R^{-1} F_{i}, \quad F_{i}=\left(F_{i 1}, \ldots, F_{i r}\right) \\
F_{i j}=\psi_{j t}+k(t)\left(b\left(u_{i+1}, \varphi_{j}\right)-l_{1}\left(\varphi_{j}\right)\right)-l\left(\varphi_{j}\right) .
\end{gathered}
$$

The latter formula almost corresponds to the iteration procedure in the proof of the fixed point theorem for the operator $S$ constructed in the proof of Theorem 1 in [20], [21], where it is proven that the process converges.

\section{Numerical Algorithm}

The algorithm is iterative and relies on the finite element method. We define a triangulation of $G$, the mesh nodes, $x_{1}, x_{2}, \ldots, x_{N}$, and the corresponding piecewise linear functions $\left\{\varphi_{i}(x)\right\}$ (thus, $\varphi_{i}\left(x_{j}\right)=\delta_{i j}$, where $\delta_{i j}$ is the Kronecker symbol. Without loss of generality, we can assume that the observation points $y_{j}$ are mesh node $x_{m_{j}}$ $(j=1,2, \ldots, r)$. An approximate solution to (12), (13) is sought in the form $u^{N}=$ $\sum_{i=1}^{N} q_{i}(t) \varphi_{i}(x)$. Assume that $a(u, \varphi)=\left(a_{0} \nabla u, \nabla \varphi\right)+\left(b_{0} \cdot \nabla u+c_{0} u, \varphi\right), b(u, \varphi)=$ $\left(a_{1} \nabla u, \nabla \varphi\right)+\left(b_{1} \cdot \nabla u+c_{1} u, \varphi\right), l(\varphi)=\left(f_{0}, \varphi\right)+l_{0}(\varphi), l_{0}(\varphi)=\int_{\Gamma} a_{0} g_{t} \varphi d \Gamma, l_{1}(\varphi)=\int_{\Gamma} a_{1} g \varphi d t$.

The vector-function $C(t)=\left(c_{1}(t), c_{2}(t), \ldots, c_{N}(t)\right)^{T}$ is a solution to the system of ordinary differential equations

$$
A C_{t}+k(t) B C=F_{0}+F_{1}, C(0)=\left(u_{0}\left(x_{1}\right), u_{0}\left(x_{2}\right), \ldots, u_{0}\left(x_{N}\right)\right)^{T},
$$

where $A, B$ are matrices with the entries $a_{i j}=a\left(\varphi_{j}, \varphi_{i}\right), b_{i j}=b\left(\varphi_{j}, \varphi_{i}\right)$, and $F_{0}=$ $\left(F_{01}, \ldots, F_{0 N}\right)^{T}, \quad F_{0 i}(t)=l\left(\varphi_{i}\right)+k(t) l_{1}\left(\varphi_{i}\right), \quad F_{1}=\left(F_{11}, \ldots, F_{1 N}\right)^{T}$, where $F_{1 j}=$ $\sum_{k=1}^{r} q_{k}(t)\left(f_{k}, \varphi_{j}\right)$. Thus, the vector $F_{1}$ is representable as $F_{1}=R \vec{q}$, where the matrix $R=\left\{r_{i j}\right\}$ has the entries $r_{i j}=\left(f_{j}, \varphi_{i}\right)$. We thus have that

$$
A C_{t}+k(t) B C=F_{0}+R \vec{q}, C(0)=\left(u_{0}\left(x_{1}\right), u_{0}\left(x_{2}\right), \ldots, u_{0}\left(x_{N}\right)\right)^{T},
$$


To solve (22), we involve the finite difference method (FDM) (the implicit scheme) and replace (22) with the finite difference equation

$$
A_{n} \frac{C_{n}-C_{n-1}}{\tau}+k_{n} B_{n} C_{n}=F_{0, n}+R_{n} \vec{q}_{n}, C_{0}=C(0)
$$

where $n=1,2, \ldots, M, \tau=T / M$, and $F_{0 n}, A_{n}, B_{n}, R_{n}$ are the values of the right-hand side in (22), and the matrices $A, B$ at $n \tau$. We assume here that the approximation $\vec{q}_{n}$ is a piecewise constant vector-function taking the value $\vec{q}_{n}$ on $((n-1) \tau, n \tau]$. Respectively, a piecewise constant approximation of a solution $C(t)$ to $(21)$ is a piecewise constant function equal to the vector $C_{n}$ on the set $((n-1) \tau, n \tau]$. An analog of the overdetermination condition is as follows:

$$
\frac{\left(C_{n}\right)_{m_{j}}-\left(C_{n-1}\right)_{m_{j}}}{\tau}=\psi_{j t}((n-1) \tau), \quad j=1,2, \ldots, r
$$

where $\left(C_{n}\right)_{m_{j}}$ is the $m_{j}$-th coordinate of the vector $C_{n}$. From (24) we have that

$$
\psi_{j t}((n-1) \tau)+k_{n}\left(\left(A_{n}\right)^{-1} B_{n} C_{n}\right)_{m_{j}}-\left(\left(A_{n}\right)^{-1} F_{0, n}\right)_{m_{j}}=\left(\left(A_{n}\right)^{-1} R_{n} \vec{q}_{n}\right)_{m_{j}},
$$

where $j=1,2, \ldots, r$. Denote by $\alpha_{i j}^{n}$ the entries of the matrix $\left(A_{n}\right)^{-1} R_{n}$. We have that the right-hand side in (25) can be written as $S_{n} \vec{q}_{n}$ and $S_{n}$ is the matrix with entries $\beta_{j, l}^{n}=\alpha_{m_{j} l}^{n}$. The left-hand side is the vector $G_{n}$ with the coordinates $G_{j}^{n}=\psi_{j t}((n-1) \tau)+$ $k_{n}\left(\left(A_{n}\right)^{-1} B_{n} C_{n}\right)_{m_{j}}-\left(\left(A_{n}\right)^{-1} F_{0, n}\right)_{m_{j}}, j=1,2, \ldots, r$. Thus, we can consider the equation

$$
G_{n}=S_{n} \vec{q}_{n}
$$

Next, describe the numerical algorithm. First, we find the vector $\vec{q}_{0}$ from the equality

$$
G_{0}=S_{0} \vec{q}_{0}
$$

where the vector $G_{0}$ the coordinates $G_{j}^{0}=\psi_{j t}(0)+k_{0}\left(\left(A_{0}\right)^{-1} B_{0} C_{0}\right)_{m_{j}}-\left(\left(A_{0}\right)^{-1} F_{0,0}\right)_{m_{j}}$ $(j=1,2, \ldots, r)$. Next, we put $\vec{q}_{1}^{1}=\vec{q}_{0}$ and find the vector $C_{1}^{1}$ from the equality

$$
A_{n} \frac{C_{n}^{i}-C_{n-1}}{\tau}+k_{n} B_{n} C_{n}=F_{0, n}+R_{n} \vec{q}_{n}^{i}, C_{0}=C(0)
$$

where $i=1$ and $n=1$. Let $G_{n}^{i}$ be the vector with the coordinates $G_{j}=\psi_{j t}((n-1) \tau)+$ $k_{n}\left(\left(A_{n}\right)^{-1} B_{n} C_{n}^{i}\right)_{m_{j}}-\left(\left(A_{n}\right)^{-1} F_{0, n}\right)_{m_{j}}, j=1,2, \ldots, r$. Next we find the vector $\vec{q}_{1}^{2}$ from the equality

$$
G_{n}^{i}=S_{n} \vec{q}_{n}^{i+1}
$$

where $n=1$ and $i=1$. Using the vector $\vec{q}_{1}^{2}$ in (28) with $n=1$ and $i=2$ we can find the vector $C_{1}^{2}$ and so on. The process is going on until $\left\|\vec{q}_{1}^{i+1}-\vec{q}_{1}^{i}\right\|<\varepsilon$, with $\varepsilon>0$ is a given number. Next, we take $C_{1}=C_{1}^{i+1}, \vec{q}_{1}=\vec{q}^{i+1}$. Assume that we have found the vectors $C_{n-1}, \vec{q}_{n-1}$. We take $\vec{q}_{n}^{1}=\vec{q}_{n-1}$ and calculate the vector $C_{n}^{1}$ from (28) with $i=1$. Define the vector $G_{n}^{1}$ and find the vector $\vec{q}_{n}^{2}$ from (29) with $i=1$. We repeat the arguments until $\left\|\vec{q}_{n}^{i+1}-\vec{q}_{n}^{i}\right\|<\varepsilon$. In this case we put $\vec{q}_{n}=\vec{q}_{n}^{i+1}, C_{n}=C_{n}^{i+1}$. Repeating the arguments we can calculate all quantities $\vec{q}_{1}, \vec{q}_{2}, \ldots, \vec{q}_{M}, C_{1}, C_{2}, \ldots, C_{M}$. 


\section{The Results of Numerical Experiments}

In this section we analyze the results of numerical experiments. The characteristics of the computer are as follows: the processor Intel(R) Core(TM) i3-8100 CPU @ 3.60GHz 3.60GHz, 8.00 GB RAM, the 64-digit operating system Windows 10 Pro.

As a result of calculations, we obtain approximate values of a solution $(u(x, y, t), \vec{q}(t))$ of the problem (12)-(13) at points $\left(t_{1}, t_{2}, \ldots t_{N}\right)$. Here the point $(x, y)$ belongs to the unit circle centered at $(0,0)$. We present the results of calculations only for the vector-function $\vec{q}$.

To solve the problem numerically, we use two meshes for this domain with the number of nodes $N_{1}=263$ and $N_{2}=1015$ (Fig. 1).

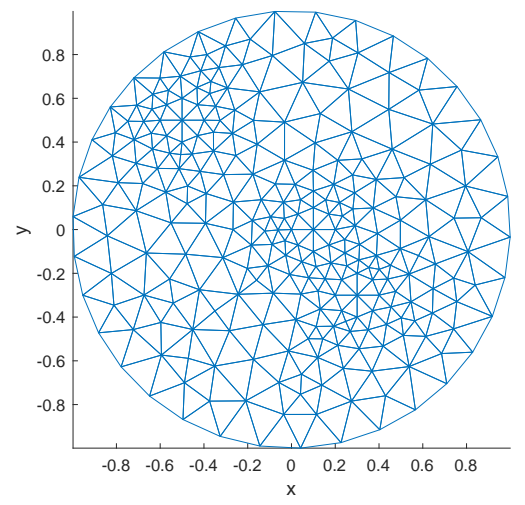

a)

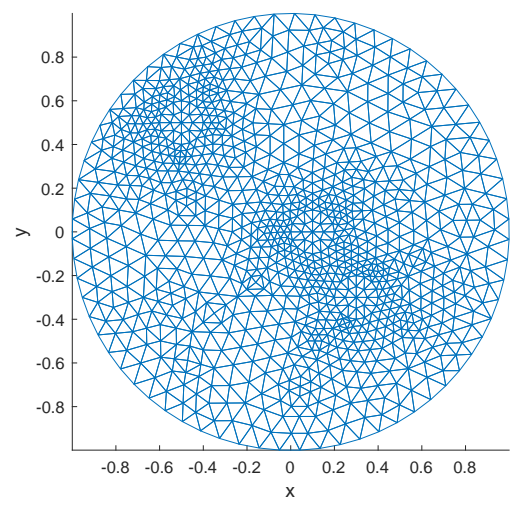

b)

Fig. 1. Meshes: a) $N_{1}=263$; b) $N_{2}=1015$

We consider the equation (12), where $r=3$. We use the following data:

the solution: $u(x, y, t)=\left(x^{2}+1\right) \cdot\left(y^{2}+1\right) \cdot(1+t)$;

the initial data: $\left.u\right|_{t=0}=\left(x^{2}+1\right) \cdot\left(y^{2}+1\right)$;

the Neumann boundary conditions: $g=2(t+1)\left(y\left(x^{2}+1\right)+x\left(y^{2}+1\right)\right)$;

the additional information: $\psi_{i}(t)=\left(x_{i}^{2}+1\right) \cdot\left(y_{i}^{2}+1\right) \cdot(1+t)$;

the unknown function: $q_{1}=1, q_{2}=t^{2}+2, q_{3}=(t-2)^{3}$,

the coefficients: $a_{0}=(t+1)\left(x^{2}+1\right), a_{1}=\left(t^{2}+y+4\right) /\left(x^{2}+1\right), b_{0,1}=x^{3} \cdot t, b_{0,2}=(x+y) \cdot t$, $b_{1,1}=y^{2} /(t+1), b_{1,2}=x t /(y+1), c_{0}=1 /\left(x^{2}+y^{2}+1\right), c_{1}=1 /(1+t) ;$

the right-hand side: $f=y^{2}-12 x^{6}\left(y^{2}+1\right)(t+1)+x\left(x^{2}+1\right)\left(y^{2}+1\right)-2\left(x^{2}+1\right)\left(x^{6}+\right.$ 1) $(t+1)-2\left(x^{6}+1\right)\left(y^{2}+1\right)(t+1)+2 t x\left(y^{2}+1\right)\left(x+x^{3}\right)-2 t x^{3}\left(x^{2}+1\right)(t+1)-8 t x^{3}\left(y^{2}+\right.$ $1)(t+1)+2 \operatorname{ty}\left(x^{2}+1\right)(x+y)+2 t x y\left(x^{2}+1\right)(t+1) /(y+1)-x\left(t^{2}+2\right)-1-y(t-2)^{3}$.

We will use the Neumann boundary conditions from (16) which are represented as

$$
\left.\frac{\partial u}{\partial n}\right|_{\Gamma}=\left(u_{x} x+u_{y} y\right)=g
$$

The additional information (14) is given at the observation point $x_{m_{1}}=\left(x_{1}, y_{1}\right)=$ $(0.3,-0.3), x_{m_{2}}=\left(x_{2}, y_{2}\right)=(0.1,0), x_{m_{3}}=\left(x_{3}, y_{3}\right)=(-0.5,0.5)$.

All numerical experiments are divided into two groups in dependence on the unknown functions $u, \vec{q}$, the boundary conditions, the noise level $\delta$, the error between iterations $\varepsilon$, the coefficients $a_{0}, a_{1}, b_{0}(x, t)=\left(b_{0,1}, b_{0,2}\right), b_{1}(x, t)=\left(b_{1,1}, b_{1,2}\right), c_{0}, c_{1}$, and the right-hand 
sides $f$. If $\delta \neq 0$ then the perturbations of the overdetermination data at the moments of time $\Delta t k, \quad k=1,2, \ldots, N\left(\Delta t\right.$ is a step in time) are defined as follows: $\tilde{\psi}_{i t}(\Delta t k)=$ $\psi_{t}(\Delta t k)\left(1+\delta\left(2 \sigma_{i k}-1\right)\right)$, where numbers $\sigma_{i k} \in[0,1]$ are determined using the random number generator of Matlab (the function rand).

First, we compare the results of calculations (Fig. 2) for two meshes mentioned above, for data without noise, i.e., $\delta=0$. Consider the segment $[0, T], T=1$, and $\Delta t=T / N$, $N=100$. We take $\varepsilon=10^{-3}$ (the error defined by the user).
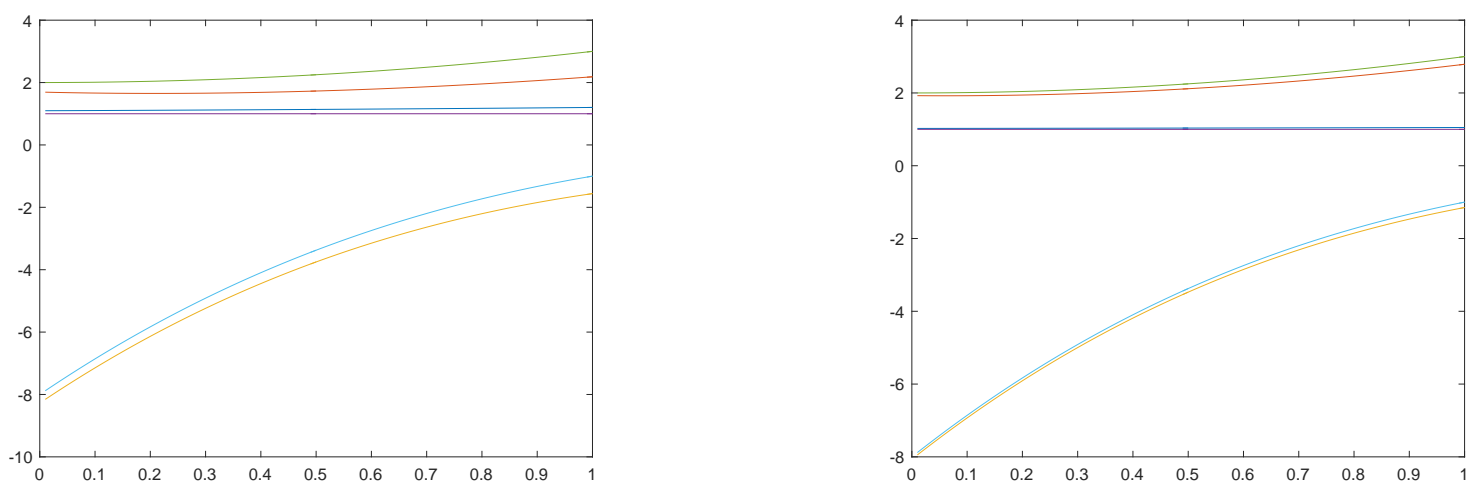

Fig. 2. Results of calculations for the meshes with $\mathrm{N}=100$

Next, we take the same meshes and other parameters but $N=400$ and we obtain the following result (Fig. 3).
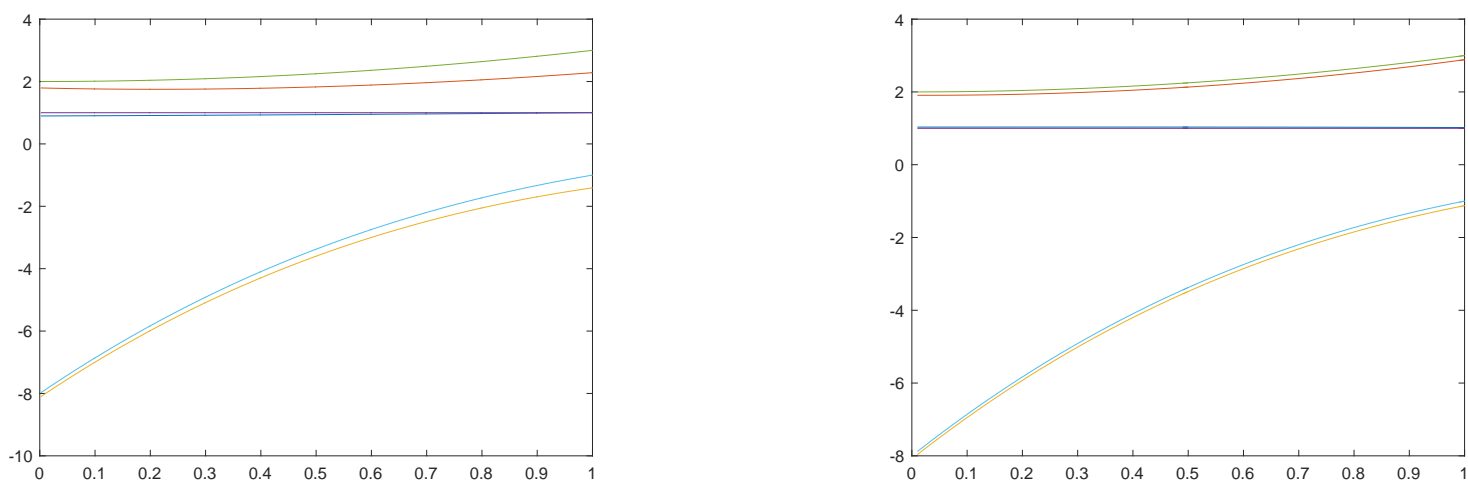

Fig. 3. Results of calculations for the meshes with $N=400$

In the following experiments, we add 1 percent random noise for the second mesh with $N=100$ and $N=400$ (Fig. 4).

Based on the results of numerical experiments for the group of data, we can conclude that the increase in the number of nodes in 4 times leads to the increase in the calculation time more than 10 times. It is lead to a significant increase in accuracy. But further splitting is already useless due to time consuming and low usability.

As we can see the decrease in the variable $\varepsilon$ does not lead to a significant increase in the accuracy and decreasing the time of calculations. 

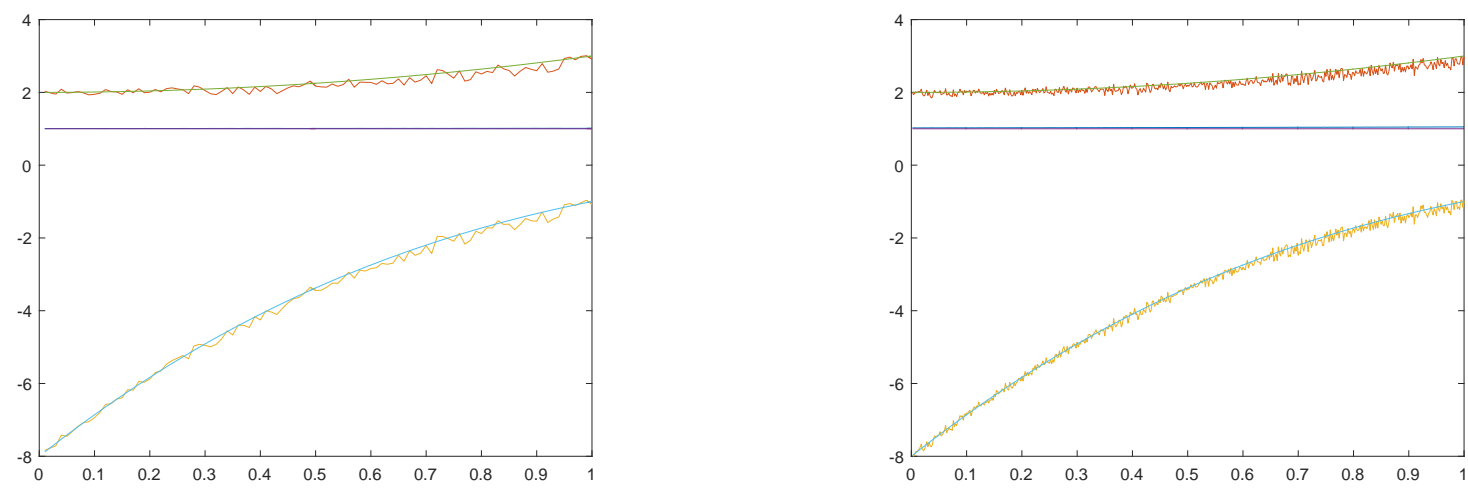

Fig. 4. Results of calculations with a random error with different $\mathrm{N}$

Summing up, we can say that the use of a grid with a large number of nodes shows better accuracy, but the time of the calculation increases by an amount equal to the ratio of the number of nodes of the grids. Increasing the time step also shows a good result, especially when adding a random error. Decreasing the variable $\varepsilon$ leads to an increase in the computation time, but does not lead to a significant increase in accuracy.

\section{Conclusions}

Under consideration is an inverse problem of recovering the right-hand side in a pseudoparabolic equation. Some theoretical results and stability estimates for solution are exposed. We propose a numerical algorithm of recovering the right-hand side with the use of the pointwise overdetermination conditions. A numerical algorithms is based on the finite element method combined with the finite difference schemes. The results of numerical experiments show a sufficiently good convergence of the algorithm.

The author was supported by the Russian Foundation for Basic Research and the government of Khanty-Mansiysk Autonomous Okrug-YuGRA (Grant 18-41-860003, $\left.r_{-} u r a l_{-} a\right)$

\section{References}

1. Sobolev S. L. Methode Nouvelle a Resoudre le Probleme de Cauchy pour les Equations Lineaires Hyperboliques Normales. Mat. Sb., 1936, vol. 1, pp. 39-72.

2. Demidenko G. V., Uspenskii S. V., [ Equations and Systems Unsolved with Respect to the Highest Derivative]. Nauchnaya Kniga Publ., Novosibirsk, 1998. (in Russian)

3. Rossby C. G. Relation between Variations in the Intensity of the Zonal Circulation of the Atmosphere and the Displacement of the Semi-Permanent Centers of Action. J. Marine Res., 1939, vol. 2, no. 1, pp. 38-55.

4. Barenblatt G. I., Zheltov Iu. P., Kochina I. N. Basic Concepts in the Theory of Seepage of Homogeneous Liquids in Fissured Rocks. J. Appl. Math. Mech., 1960, vol. 24, no. 5, pp. 852-864. 
5. Böhm M., Showalter R. E. Diffusion in Fissured Media, SIAM J. Math. Anal., 1985, vol. 16, pp. 500-509.

6. Lyubanova A. Sh., Tani A. On Inverse Problems for Pseudoparabolic and Parabolic Equations of Filtration. Inverse Problems in Science and Engineering, 2011, vol. 19, pp. 1023-1042. DOI: 10.1080/17415977.2011.569712

7. Sveshnikov A. G., Alshin A. B., Korpusov M. O., Pletner U. D. [Linear and Nonlinear Sobolev-Type Equations]. Fizmatlit Publ., Moscow, 2007. (in Russian)

8. Sviridyuk G. A., Fedorov V. E. Linear Sobolev Type Equations and Degenerate Semigroups of Operators. VSP, Berlin, Boston: 2003.

9. Favini A., Yagi A., Degenerate Differential Equations in Banach Spaces. Marcel Dekker, Inc., N.Y., 1999.

10. Gaewskii H., Greger K., Zaharias K., [Nonlinear Operator Equations and Operator Differential Equations]. Mir Publ., Moscow, 1978. (in Russian)

11. Rundell W. Determination of an Unknown Nonhomogeneous Term in a Linear Partial Differential Equation from Overspecified Boundary Data. Appl. Anal., 1980, vol. 10, pp. 231-242.

12. Asanov A., Atamanov E. R., Nonclassical and Inverse Problems for Pseudoparabolic Equations. De Gruyter, Berlin; Boston, 1997.

13. Favini A., Lorenzi A., Differential Equations. Inverse an Direct Problems. Tylor \& Francis Group, LLC, New York, 2006.

14. Al-Horani M., Favini A. Identification Problem for First-Order Degenerate Differential Equations. J. of Optimization Theory and Applications, 2006, vol. 130, no. 1, pp. 41-60. DOI: 10.1007/s10957-006-9083-y

15. Chen F. Q., Chen Y. S., Wu Z. Q. Global Solution of the Inverse Problem for a Class of Nonlinear Evolution Equations of Dispersive Type. Applied Mathematics and Mechanics, 2002, vol. 23, no 2, pp. 150-154. DOI: 10.1007/BF02436556

16. Lyubanova A. Sh. Identification of a Coefficient in the Leading Term of a Pseudoparabolic Equation of Filtration. Siberian Mathematical Journal, 2013, vol. 54, pp. 1046-1058. DOI: 10.1134/S003744661

17. Lyubanova A. Sh., Velisevich A. V. Inverse Problems for the Stationary and Pseudoparabolic Equations of Diffusion. Applicable Analysis, 2019, vol. 98, no. 11, pp. 1997-2010. DOI: 10.1080/00036811.2018.1442001

18. Lyubanova A. Sh. The Inverse Problem for the Nonlinear Pseudoparabolic Equation of Filtration Type. J. of Siber. Federal University. Mathematics $\&$ Physics, 2017, vol. 10, no. 1, pp. 4-15. DOI: 10.17516/1997-1397-2017-10-1-4-15

19. Shergin S. N., Pyatkov S. G. On Some Classes of Inverse Problems for Pseudoparabolic Equations. Matem. Zam. SVFU, 2014, vol. 10, no. 2, pp. 106-116. (in Russian)

20. Pyatkov S. G., Shergin S. N. On Some Mathematical Models of Filtration Theory. Bulletin of the South Ural State University. Series: Mathematical Modeling, Programming and Computer Software, 2015, vol. 8, no. 2, pp. 105-116. DOI: $10.14529 / \mathrm{mmp} 150209$ 
21. Shergin S. N., Safonov E. I., Pyatkov S. G. On Some Inverse Coefficient Problems with the Pointwise Overdetermination for Mathematical Models of Filtration. Bulletin of the South Ural State University. Series: Mathematical Modeling, Programming and Computer Software, 2019, vol. 12, no. 1, pp. 82-95. DOI: 10.14529/mmp190107

22. Kabanikhin S. I., Inverse and Ill-Posed Problems. De Gruyter, Berlin; Boston, 2012.

23. Samarskii A. A. Vabishchevich P. N. Numerical Methods for Solving Inverse Problems of Mathematical Physics. De Gruyter, Berlin, Boston, 2007.

24. Vabishchevich P. N., Vasil'ev V. I., Vasil'eva M. V., Nikiforov L. Ya. Numerical Solution of an Inverse Filtration Problem. Lobachevskii Journal of Mathematics, 2016, vol. 37 , no. 6, pp. 777-786. DOI: 10.1134/S1995080216060056

25. Amirali I., Amiraliyev G. M., Cakir M., Cimen E. Explicit Finite Difference Methods for the Delay Pseudoparabolic Equations. Scientific World Journal, 2014, vol. 2014, art.no. 497393. DOI: 10.1155/2014/497393

26. Ewing R. E. Numerical Solution of Sobolev Partial Differential Equations. Siam J. Numer. Anal., 1975, vol. 12, pp. 345-363.

27. Cuesta C. M., Pop I. S. Numerical Schemes for a Pseudo-parabolic Burgers Equation, Discontinuous Data and Long-Time Behaviour. J. of Comp. and Appl. Math., 2009, vol. 224, pp. 269-283. DOI: 10.1016/j.cam.2008.05.001

28. Beshtokov M. Kh. Differential and Difference Boundary Value Problem for Loaded Third-Order Pseudo-Parabolic Differential Equations and Difference Methods for Their Numerical Solution. Computational Mathematics and Mathematical Physics, 2017, vol. 57, pp. 1973-1993. DOI: 10.1134/S0965542517120089

29. Vabishchevich P. N., Grigorev A. V. Splitting Schemes for Pseudoparabolic Equations. Differential Equations, 2013, vol. 49, pp. 807-814. DOI: 10.1134/S0012266113070033

30. Luoa Z. D. Teng F. A Reduced-Order Extrapolated Finite Difference Iterative Scheme Based on POD Method for 2D Sobolev Equation. Applied Mathematics and Computation, 2018, vol. 329, pp. 374-383. DOI: 10.1016/j.amc.2018.02.022

31. Xia H., Luo Z. An Optimized Finite Difference Crank-Nicolson Iterative Scheme for the 2D Sobolev Equation. Advances in Difference Equations, 2017, vol. 2017, art.no. 196. DOI: $10.1186 / \mathrm{s} 13662-017-1253-8$

32. Keller A. V., Zagrebina S. A., Some Generalizations of the Schowalter-Sidorov Problem for Sobolev-Type Models. Bulletin of the South Ural State University. Series: Mathematical Modeling, Programming and Computer Software, 2015, vol. 8, pp. 5-23. DOI: $10.14529 / \mathrm{mmp} 150201$

33. Hasan A., Aamo A. M., Foss B. Boundary Control for a Class of PseudoParabolic Differential Equations. Systems \& Control Letters, 2013, vol. 62, pp. 63-69. DOI: $10.1016 /$ j.sysconle.2012.10.009

34. Bukhgeim A. L., Kalinina N. I. Global Convergence of the Newton Method in the Inverse Problems of Memory Reconstruction. Siber. Math. J., 1997, vol. 38, pp. 881-895. DOI: 10.1007/BF02673029

35. Triebel H., Interpolation Theory, Function Spaces, Differential Operators, NorthHolland Publishing, Amsterdam, 1978. 
36. Al'shin A. B., Korpusov M. O., Sveshnikov A. G., Blow-up in Nnonlinear Sobolev Type Equations. De Gruyter, Berlin; N.Y., 2011.

37. Zamyshlyaeva A. A., Sviridyuk G. A. Nonclassical Equations of Mathematical Physics. Linear Sobolev Type Equations of Higher Order. Bulletin of the South Ural State University. Series: Mathematics. Mechanics. Physics, 2016, vol. 8, no. 4 pp. 5-16. DOI: $10.14529 /$ mmph160401 (in Russian)

38. Sviridyuk G. A., Zagrebina S. A. Nonclassical Mathematical Physics Models. Bulletin of the South Ural State University. Series: Mathematical Modeling, Programming and Computer Software, 2012, vol. 299, no. 40 pp. 7-18. (in Russian)

39. Sviridyuk G. A., Manakova N. A., Gavrilova O. V. Numerical Study of One Fitz Hugh Nagumo Model. [Mathematical Methods in Engineering and Technology], 2016, vol. 92, no. 10, pp. 3-6. (in Russian)

Sergey N. Shergin, PhD Student, Yugra State University (Khanty-Mansiysk, Russian Federation),ssn@ugrasu.ru

Received August 27, 2019

УДК 517.956

DOI: $10.14529 /$ jcem190304

\title{
ЧИСЛЕННЫЙ АЛГОРИТМ ДЛЯ НЕКОТОРОЙ ОБРАТНОЙ ЗАДАЧИ ФИЛЬТРАЦИИ С ТОЧЕЧНЫМ ПЕРЕОПРЕДЕЛЕНИЕМ
}

\section{С. Н. Шергин}

\begin{abstract}
Рассматривается обратная задача о восстановлении правой части в псевдопараболическом уравнии фильтрации с использованием точечного переопределения. Приводятся теоремы существования и единственности, которые являются основой численного алгоритма восстановления правой части (функции источника) и решения. Задача является корректной и имеет место оценка устойчивости. Задача может быть сведена к интегральному уравнению типа Вольтерра, где оператор имеет малую норму на малых промежутках времени. Используется метод конечных элементов для того, чтобы свести задачу к системе обыкновенных дифференциальных уравнений, которая решается методом конечных разностей. При построении алгоритма используется идея схемы предиктор-корректор. Представлены результаты численных экспериментов. Результаты показывают хорошую сходимость алгоритма к решению.

Ключевые слова: обратная задача; псевдопараболическое уравнение; фильтрачия; трещиноватая среда; численное решение.
\end{abstract}

\section{Литература}

1. Sobolev, S. L. Methode Nouvelle a Resoudre le Probleme de Cauchy pour les Equations Lineaires Hyperboliques Normales / S. L. Sobolev // Mat. Sb. - 1936. - V. 1. P. 39-72. 
2. Демиденко, Г. В. Уравнения и системы, не разрешенные относительно старшей производной / Г. В. Демиденко, С. В. Успенский. - Новосибирск: Научная книга, 1998.

3. Rossby, C. G. Relation between Variations in the Intensity of the Zonal Circulation of the Atmosphere and the Displacement of the Semi-Permanent Centers of Action / C. G. Rossby // J. Marine Res. - 1939. - V. 2, № 1. - P. 38-55.

4. Barenblatt, G. I. Basic Concepts in the Theory of Seepage of Homogeneous Liquids in Fissured Rocks / G. I. Barenblatt, Iu. P. Zheltov, I. N. Kochina // Appl. Math. Mech. - 1960. - V. 24, № 5. - P. 852-864.

5. Böhm, M. Diffusion in Fissured Media / M. Böhm, R. E. Showalter // SIAM J. Math. Anal. - 1985. - V. 16. - P. 500-509.

6. Lyubanova, A. Sh. On Inverse Problems for Pseudoparabolic and Parabolic Equations of Filtration / A. Sh. Lyubanova, A. Tani // Inverse Problems in Science and Engineering. - 2011. - V. 19, № 7. - P. 1023-1042.

7. Свешников, А. Г. Линейные и нелинейные уравнения Соболевского типа / А. Г. Свешников, А. Б. Альшин, М. О. Корпусов, Ю. Д. Плетнер. - Москва: ФМЛ, 2007.

8. Sviridyuk, G. A., Linear Sobolev Type Equations and Degenerate Semigroups of Operator / G. A. Sviridyuk, V. E. Fedorov. - Utrecht: VSP, 2003.

9. Favini, A. Degenerate Differential Equations in Banach Spaces / A. Favini, A. Yagi. N.Y.: Marcel Dekker, Inc., 1999.

10. Гаевский, Х. Нелинейные операторные уравненияи операторные дифференциальные уравнения / Х. Гаевский, К. Грегер, К. Захариас. - Москва: Мир, 1978.

11. Rundell, W. Determination of an Unknown Nonhomogeneous Term in a Linear Partial Differential Equation from Overspecified Boundary Data / W. Rundell // Appl. Anal. - 1980. - V. 10. - P. 231-242.

12. Asanov, A. Nonclassical and Inverse Problems for Pseudoparabolic Equations / A. Asanov, E. R. Atamanov. - De Gruyter, 1997.

13. Favini, A. Differential Equations. Inverse an Direct Problems / A. Favini, A. Lorenzi.-Tylor \& Francis Group, LLC, 2006.

14. Al-Horani, M. Identification Problem for First-Order Degenerate Differential Equations / M. Al-Horani, A. Favini // J. of Optimization Theory and Applications. 2006. - V. 130. - P. 41-60.

15. Chen, F. Q. Global Solution of the Inverse Problem for a Class of Nonlinear Evolution Equations of Dispersive Type / F. Q. Chen, Y. S. Chen, Z. Q. Wu // Applied Mathematics and Mechanics. - 2002. - V. 23, № 2. - P. 150-154.

16. Любанова, А.Ш. Идентификация коэффициента в старшем члене псевдопараболического уравнения типа фильтрации / А. Ш. Любанова // Сибирский математический журнал. - 2013. - Т. 6. - С. 1046-1058.

17. Lyubanova, A. Sh. Inverse Problems for the Stationary and Pseudoparabolic Equations of Diffusion / A. Sh. Lyubanova, A. V. Velisevich // Applicable Analysis. - 2019. V. 98, № 11. - P. 1997-2010. 
18. Lyubanova, A.Sh. The Inverse Problem for the Nonlinear Pseudoparabolic Equation of Filtration Type / A.Sh. Lyubanova // J. of Siber. Federal University. Mathematics \& Physics. - 2017. - V. 10, № 1. - P. 4-15.

19. Шергин, С. Н. О некоторых классах обратных задач для псевдопараболических уравнений / С. Н. Шергин, С. Г. Пятков // Математические заметки СВФУ. 2014. - T. 21, № 2. - C. 106-116.

20. Шергин, С. Н. Некоторые математические модели фильтрационной теории / С. Н. Шергин, С. Г. Пятков // Вестник ЮУрГУ. Серия: Математическое моделирование и программирование. - 2015. - Т. 8, № 2. - С. 105-116.

21. Шергин, С. Н. О некоторых коэффициентных обратных задачах с точечным переопределением для математических моделей фильтрации / С. Н. Шергин, С. Г. Пятков, Е. И. Сафонов // Вестник ЮУрГУ. Серия: Математическое моделирование и программирование. - 2019. - Т. 12, № 1. - С. 82-95.

22. Kabanikhin, S. I. Inverse and Ill-Posed Problems / S. I. Kabanikhin. - Berlin, Boston: De Gruyter, 2012.

23. Samarskii, A. A. Numerical Methods for Solving Inverse Problems of Mathematical Physics / A. A. Samarskii, P. N. Vabishchevich. - Berlin, Boston: De Gruyter, 2007.

24. Vabishchevich, P. N. Numerical Solution of an Inverse Filtration Problem P. N. Vabishchevich, V. I. Vasil'ev, M. V. Vasil'eva, L. Ya. Nikiforov // Lobachevskii Journal of Mathematics. - 2016. - V. 37, № 6. - P. 777-786.

25. Amirali, I. Explicit Finite Difference Methods for the Delay Pseudoparabolic Equations / I. Amirali, G. M. Amiraliyev, M. Cakir, E. Cimen // Scientific World Journal. - 2014. - V. 2014. - A/N 497393.

26. Ewing, R. E. Numerical Solution of Sobolev Partial Differential Equations R. E. Ewing // Siam J. Numer. Anal. - 1975. - V. 12. - P. 345-363.

27. Cuesta, C. M. Numerical Schemes for a Pseudo-Parabolic Burgers Equation / C. M. Cuesta, I. S. Pop // J. of Comp. and Appl. Math. - 2009. - V. 224. - P. 269-283.

28. Beshtokov, M. Kh. Differential and Difference Boundary Value Problem for Loaded Third-Order Pseudo-Parabolic Differential Equations and Difference Methods for Their Numerical Solution / M. Kh. Beshtokov // Computational Mathematics and Mathematical Physics. - 2017. - V. 57. - P. 1973-1993.

29. Vabishchevich, P. N. Splitting Schemes for Pseudoparabolic Equations P. N. Vabishchevich, A.V. Grigor'ev // Differential Equations. - 2013. - V. 49. P. 807-814.

30. Luoa, Z. D. A Reduced-Order Extrapolated Finite Difference Iterative Scheme Based on POD Method for 2D Sobolev Equation / Z. D. Luoa, F. Teng // Applied Mathematics and Computation. - 2018. - V. 329. - P. 374-383.

31. Xia, H. An Optimized Finite Difference Crank-Nicolson Iterative Sheme for the 2D Sobolev Equation / H. Xia, Z. Luo // Advances in Difference Equations. - 2017. V. 2017. - A/N 196.

32. Keller, A. V. Some Generalizations of the Schowalter-Sidorov Problem for SobolevType Models / A. V. Keller, S. A. Zagrebina // Вестник ЮУрГУ. Серия: Математическое моделирование и программирование. - 2015. - V. 8, № 2. - С. 5-23. 
33. Hasan, A. Boundary Control for a class of Pseudo-Parabolic Differential Equations A. Hasan, A. M. Aamo, B. Foss // Systems \& Control Letters. - 2013. - V. 62. P. 63-69.

34. Bukhgeim, A. L. Global Convergence of the Newton Method in the Inverse Problems of Memory Reconstruction / A. L. Bukhgeim, N. I. Kalinina // Siber. Math. J. 1997. - V. 38. - P. 881-895.

35. Triebel, H. Interpolation Theory, Function Spaces, Differential Operators H. Triebel. - Amsterdam: North-Holland Publishing, 1978.

36. Al'shin, A. B. Blow-up in Nonlinear Sobolev Type Equations / A. B. Al'shin, M. O. Korpusov, A. G. Sveshnikov. - Berlin;N.Y.: De Gruyter, 2011.

37. Замышляева, А. А. Неклассические уравнения математической физики. Линейные уравнения соболевского типа высокого порядка / А. А. Замышляева, Г. А. Свиридюк // Вестник ЮУрГУ. Серия: Математика. Механика. Физика. 2016. - T. 8, № 4. - C. 5-16.

38. Свиридюк, Г. А. Неклассические модели математической физики / Г. А. Свиридюк, С. А. Загребина // Вестник ЮУрГУ. Серия: Математическое моделирование и программирование. - 2012. - № 14. - С. 7-18.

39. Свиридюк, Г.А. Численное исследование одной модели Фитц Хью - Нагумо / Г. А. Свиридюк, Н. А. Манакова, О. В. Гаврилова // Математические методы в технике и технологиях - ММТТ. - 2016 - Т. 92, №10. - С. 3-6.

Шергин Сергей Николаевич, аспирант, Югорский государственный университет, (ә. Ханты-Мансийск, Российская Федерация), ssn@ugrasu.ru

Поступила в редакцию 27 августа 2019 г. 